\title{
Recovery and Modification of Waste Tire Particles and Their Use as Reinforcements of Concrete
}

\author{
Eduardo Sadot Herrera-Sosa, ${ }^{1}$ Gonzalo Martínez-Barrera, ${ }^{2}$ Carlos Barrera-Díaz, ${ }^{3}$ \\ Epifanio Cruz-Zaragoza, ${ }^{4}$ and Fernando Ureña-Núñez ${ }^{5}$ \\ ${ }^{1}$ Facultad de Química, Universidad Autónoma del Estado de México, Paseo Colón Esquina Paseo Tollocan S/N, \\ 50180 Toluca, MEX, Mexico \\ ${ }^{2}$ Laboratorio de Investigación y Desarrollo de Materiales Avanzados (LIDMA), Facultad de Química, \\ Universidad Autónoma del Estado de México, Km 12 de la Carretera Toluca-Atlacomulco, 50200 San Cayetano, MEX, Mexico \\ ${ }^{3}$ Centro Conjunto de Investigación en Química Sustentable, Universidad Autónoma del Estado de México-Universidad Nacional \\ Autónoma de México (UAEM-UNAM), Carretera Toluca-Atlacomulco, Km 14.5, Unidad El Rosedal, 50200 Toluca, MEX, Mexico \\ ${ }^{4}$ Unidad de Irradiación y Seguridad Radiológica, Instituto de Ciencias Nucleares, Universidad Nacional Autónoma de México, \\ A.P. 70-543, 04510 Mexico, DF, Mexico \\ ${ }^{5}$ Instituto Nacional de Investigaciones Nucleares, Carretera México-Toluca S/N, La Marquesa, 52750 Ocoyoacac, MEX, Mexico
}

Correspondence should be addressed to Gonzalo Martínez-Barrera; gonzomartinez02@yahoo.com.mx

Received 5 May 2015; Accepted 22 June 2015

Academic Editor: Angel Concheiro

Copyright (C) 2015 Eduardo Sadot Herrera-Sosa et al. This is an open access article distributed under the Creative Commons Attribution License, which permits unrestricted use, distribution, and reproduction in any medium, provided the original work is properly cited.

\begin{abstract}
Environmental pollution caused by solid wastes is increasing in the last decades; one of these is referred to automotive tires, which are recycled by different methods, including mechanical grinding. One of the most recurrent applications is to use recycled particles as fillers in building materials, as hydraulic concrete. Nevertheless, detrimental values on the mechanical properties are obtained when they are added. For solving these problems, in this work, a novel proposal is to modify the physicochemical properties of the waste automotive tire particles, previously obtained by grinding process, by using gamma irradiation in order to use them as reinforcements of hydraulic concrete. The results show that improvements on the mechanical properties depend of gamma irradiation as well as concentration and size of waste tire particles. Moreover, SEM images are related to mechanical properties; for instance, rough surface of the tire particles changes when applying irradiation; more smooth surfaces are created, due to the crosslinking of polymer chains. Nevertheless, for higher doses, cracks are observed which are produced by scission of the polymer chains.
\end{abstract}

\section{Introduction}

One of the major environmental problems around the world is the final disposal of waste of automotive tires. Nevertheless, a lack of information is concerning end-of-life of tire management issues. Innovative solutions are developed to meet the challenge of tire disposal problem. They include update of the life cycles assessments, showing the benefits of the recycling, and recovery actions. Moreover, it is necessary to have in mind how waste tires can be converted into a valuable resource [1]. Recycling of such materials has been carried out by different processes, including (a) landfilling, which diminishes in some countries due to new laws that forbid any new landfill; (b) producing powder richer in carbon compounds by pyrolysis process, which consist in the decomposition of the organic materials by heating at $400^{\circ} \mathrm{C}$ in absence of oxygen; pyrolysis sometimes is not economically viable due to low quality final products; nevertheless, it is possible to obtain three different phases through all processes, (1): solid black phase composed by $\mathrm{ZnO}$ and $\mathrm{ZnS}$; (2): gaseous phase containing aromatic compounds; and (3): liquid phase with heavy and light oils [2-4]; (c) using as fuel in cement kilns, whose cost is lower than raw tire materials, which is an example of downcycling process [4]; (d) recycling by shredding process, where waste tires particles require having certain size for specific applications, varying from $0.15 \mathrm{~mm}$ to 
$19 \mathrm{~mm}$; after shredding an electromagnetic process is applied for separation of rubber particles and steel fibers, for reusing them in several applications, for making rubber products such as floor mats, carpet padding, and plastic products, and as a substitute of fine aggregate in concrete $[5,6]$.

Recycled waste tires have been used in the construction industry; some examples of their uses are (a) waste steel fibers from recycled tires as mechanical reinforcement of concrete, which makes possible the improvement of mechanical performances of the concrete [7-9]; (b) recovered rubber as replacement of natural aggregates (fine and coarse), in which the elasticity features were improved and a lower diminution on the compressive strength and brittleness values were found; moreover, by adding rubber particles the reduction of the water absorption was possible; thus a better protection of the steel reinforcement against corrosion is obtained, as well as reduction in the structural weight [10-15]; (c) partial replacement, either sand or cement, by crumb rubber or powder rubber in concrete. The fracture characteristics of concrete were improved when adding crumb rubber; nevertheless, flexural strength was diminished. Moreover, light increment is done when adding powder. Other study points out large reductions in the strength and tangential modulus of elasticity as well as in the brittle behavior of the concrete when adding tire chips and crumb rubber particles [16, 17]; (d) recycling tires as foundation pad for rotating machinery and as vibrations damper in the railway station or where impact resistance, energy absorption, or blast is required [18]; (e) the incorporation of crumb rubber aggregates from worn tires as lightweight aggregate in cement based materials which endows enhanced acoustic and thermal conductivity characteristics; moreover, when crumb rubber is used as insulation material allows potential savings on energy [19].

Although some advantages are obtained when adding recycled materials as rubber tire particles for improvement of the toughness of concrete, they present some disadvantages as lower values on the compressive strength, which should be attended. One alternative is the use of gamma radiation. Recent works have studied the effects of gamma radiation on compressive properties of polymer concrete; in one of them, the results show more resistance to crack propagation; moreover, compressive strain and the elasticity modulus depend on the combination of the particle sizes and the radiation dose [20].

The gamma radiation $(\gamma)$ is a type of high electromagnetic energy radiation, generally produced by radioactive elements or subatomic processes such as the annihilation of a positronelectron pair. One important characteristic is its capacity to penetrate matter deeper than alpha or beta radiation. In general, the gamma rays strike and pass through the material; it depends on the photon energies, thickness, or density of the materials.

Application of gamma radiation in polymeric materials causes three different processes: cross-linking or scission of polymer chains and graft polymerization. The permanence of any of these processes depends on the nature of the radiation, the chemical structure of the polymer, and the applied dose [21]. In general, molecular weight changes are produced after chemical reactions; content of gels with low molecular weight is obtained. After irradiating physical properties are affected.

For example, the vulcanization of chlorine butyl rubbers by using gamma radiation decreases the tensile strength and elongation at break up to $25 \mathrm{kGy}$, but after this dose stability of such properties is observed, up to $200 \mathrm{kGy}$. Moreover, thermal stability is reduced through the degradation and scission of molecular chains [22]. In another study, polydimethylsiloxane rubber foams were gamma irradiated and their mechanical properties and chemical structure were evaluated, through compression test, infrared attenuated total reflectance spectroscopy (ATR), and X-ray induced photoelectron spectroscopy (XPS). The results show a higher crosslinking of polymer chains when increasing the irradiation dose; thus foams became harder [23].

The high-energy radiation is not frequent in the preparation of composites; nevertheless it has special advantages in the control polymerization because it can be initiated uniformly within small thicknesses of material. This process, compared to thermal process or chemical attack, presents several advantages; for example, initiating radiation requires no activation energy and does not require catalysts or additives to initiate the reaction; the initiation is homogeneous throughout the system, the process can be carried out at any temperature and can be interrupted at a specific reaction time, the termination reaction is practically controlled, the polymer can be analyzed to a specific reaction step, and during temperature initialization reaction is maintained, unlike the one presented in a conventional exothermic curing without irradiation, and, above all, it is faster spending less time and money $[21,24,25]$.

Some studies covered the effects of gamma radiation on composite materials, for example, on the mechanical properties and durability of cement concretes. Some applications include concrete as material for nuclear power reactors; for this purpose the specimens were submitted to dosages from $227 \mathrm{MGy}$ and $470 \mathrm{MGy}$ with a dose rate of $5.0 \mathrm{kGy} / \mathrm{h}$. The results show a diminution of about $10 \%$ on the elastic and tensile properties, as well as loss of weight, caused by one or more of the following mechanisms: (a) "natural" drying (including gamma heating); (b) radiolysis-induced accelerated drying (where large gas is released); (c) radiolysisinduced carbonation; and (d) degradation of the calciumbearing cement hydrates [26, 27].

Another study is related to cement concrete and irradiated nylon fibers; it shows higher compressive strength values, when adding nylon irradiated fibers at $50 \mathrm{kGy}$. Load transfer mechanism between the concrete and fibers under loading is seen. Moreover, a reinforced concrete is created with high elastic modulus and high deformability. Furthermore, $50 \mathrm{kGy}$ seems to be the dose at which the reaction mechanism changes from cross-linking to chain scission. Ionizing energy generates more contact points on the fiber surfaces and in consequence a larger contact area between the fibers and the concrete phase [28]. Another study is devoted to polymer-ceramic composite material, as gypsum/poly(methyl) acrylate composite where the yield of polymerization increased up to $88 \%$ with increasing radiation dose and leveled off at a dose around 4 kGy [29]. 
TABLE 1: Components of the concrete for producing $1 \mathrm{~m}^{3}$.

\begin{tabular}{lcccccc}
\hline Mix code & Waste tire $($ Vol\%) & Waste tire $(\mathrm{kg})$ & Portland cement $(\mathrm{kg})$ & Sand $(\mathrm{kg})$ & Gravel $(\mathrm{kg})$ & Water $(\mathrm{kg})$ \\
\hline M-0 & 0 & 0 & 337.1 & 758.5 & 662.6 & 286.3 \\
\hline M-10-7 & 10 & 36.2 & 337.1 & 596.4 & 758.5 & 278.4 \\
M-20-7 & 20 & 72.4 & 337.1 & 530.1 & 758.5 & 270.6 \\
M-30-7 & 30 & 108.7 & 337.1 & 463.8 & 758.5 & 262.7 \\
\hline M-10-20 & 10 & 47.2 & 337.1 & 596.4 & 758.5 \\
M-20-20 & 20 & 94.5 & 337.1 & 530.1 & 758.5 & 278.4 \\
M-30-20 & 30 & 141.7 & 337.1 & 463.8 & 758.5 & 270.6 \\
\hline
\end{tabular}

Modifications on the cement and different mineral aggregates have been done by using gamma radiation; such materials are mixing into the concrete. In other cases all concrete components are mixed and then concrete specimens are irradiated. Both kinds of concretes are evaluated by mechanical tests. The results are different, and the scanning electron microscopy has been a good tool to evaluate the contribution of each component in nonirradiated and irradiated concretes. After mechanical testing, morphological characterization on some fractured cement concrete pieces is carried out. SEM technique provides good images of distribution of dispersed phases in a matrix [30].

The effects of gamma irradiation on the compressive properties of polymer concretes show that the compressive strain and the elasticity modulus depend on the particle sizes used and the applied radiation dose; in particular, more resistance to crack propagation is obtained. Alternative studies were using recycled polymers and gamma radiation, for example, (a) polymer concrete with recycled high density polyethylene (HDPE) and tire rubber particles, irradiated from 25 to $50 \mathrm{kGy}$. The results show significant increase on the impact strength and in the elongation at break; such improvements were attributed to the good adhesion between tire rubber particles and the polymer matrix [31]; (b) polymer concrete with waste tire rubber and styrene butadiene rubber (SBR) improved its tensile strength, elongation, and heat resistance up to $75 \mathrm{kGy}$ [32].

This study attempts to use gamma irradiation as modifier of the physicochemical properties of waste automotive tire particles and use them as reinforcement of cement concrete and in consequence improve their mechanical properties. This investigation promotes the use of waste materials in the construction industry, as one alternative for reducing environmental pollution.

\section{Experimental}

2.1. Design and Manufacture of Concrete. All mixes were elaborated with Portland cement CPC-30Rs and gravel and water (according to ASTM C 150 cement type I) [33]. The objective was to obtain a mix with $24.5 \mathrm{MPa}$ in compression strength at 28 days of curing, according to ACI 211.1 standard [34]. Physical properties of the concrete components and the sieve analyses of fine and coarse aggregates are described in [35].

2.2. Mixing, Casting, and Curing Specimens. Plain concrete mixtures were prepared with dry aggregates (fine and coarse), cement, and water. Cement was mixed with addition of $85 \%$ of water; after mixing by one minute, $15 \%$ of water was added and mixed for a total time of 5 minutes, in order to prevent fresh concrete from segregation.

Concrete with or without irradiated-tire particles was elaborated. For each concrete mixture ten specimens were casted in cylindrical molds of $150 \mathrm{~mm}$ diameter and $300 \mathrm{~mm}$ height, as well as two beams of $150 \times 150 \times 600 \mathrm{~mm}$. After 24 hours, they were placed in a controlled temperature room at $23.0 \pm 2.0^{\circ} \mathrm{C}$ and $95 \%$ of relative humidity. Cured process was performed in accordance with ASTM C511 standard [36].

The component concentrations of the concrete are shown in Table 1. Regarding the manufactured concrete replacing sand by waste tire particles, two different waste tire particle sizes were used $(2.8 \mathrm{~mm}$ (mesh 7) and $0.85 \mathrm{~mm}$ (mesh 20)), having an approximate waste particle size ratio of $1: 3$. Moreover, three different concentrations of waste tire particles 10,20 , and $30 \%$ by volume were used. The mix code was labeled as Mix-Concentration-Mesh; for example, M-107 specimens means mix with $10 \%$ of waste tire and mesh size 7. The water/cement ratio was kept constant at 0.54 .

2.3. Irradiation Procedure. Waste tire particles were irradiated at 200 and $300 \mathrm{kGy}$ with a ratio of $4 \mathrm{kGy} / \mathrm{h}$. Then, they were added to the concrete mix; finally, after mixing, the concrete was casted in molds. For irradiation process an irradiator Gamma Beam 651-PT loaded with ${ }^{60} \mathrm{Co}$ pencils was used; it is located at the Institute of Nuclear Sciences of the National Autonomous University of Mexico.

2.4. Mechanical Tests. Concrete specimens were tested after 28 days of curing time. Testing tolerance allowed was 28 days \pm 12 hours according to ASTM C/192M-00 standard [37]. Compressive strength evaluation was carried out in a universal testing machine Controls 047H4 (Milano, Italy) with capacity of $2000 \mathrm{kN}$ [38]. The modulus of elasticity was determined from the slope of the stress-strain curve; while the flexural strength by using Elvec 72-4 machine with capacity of $10 \mathrm{kN}$ [39]. The pulse velocity evaluation was carried out with an ultrasonic pulse velocity tester Controls $58 \mathrm{E} 0048$ with transmitter and receiver head $(54 \mathrm{kHz})$ and pulse rate of $1 / \mathrm{s}[40]$.

\section{Results}

3.1. Unit Weight. The unit weights of concretes are shown in Figure 1. These results are discussed in terms of three 


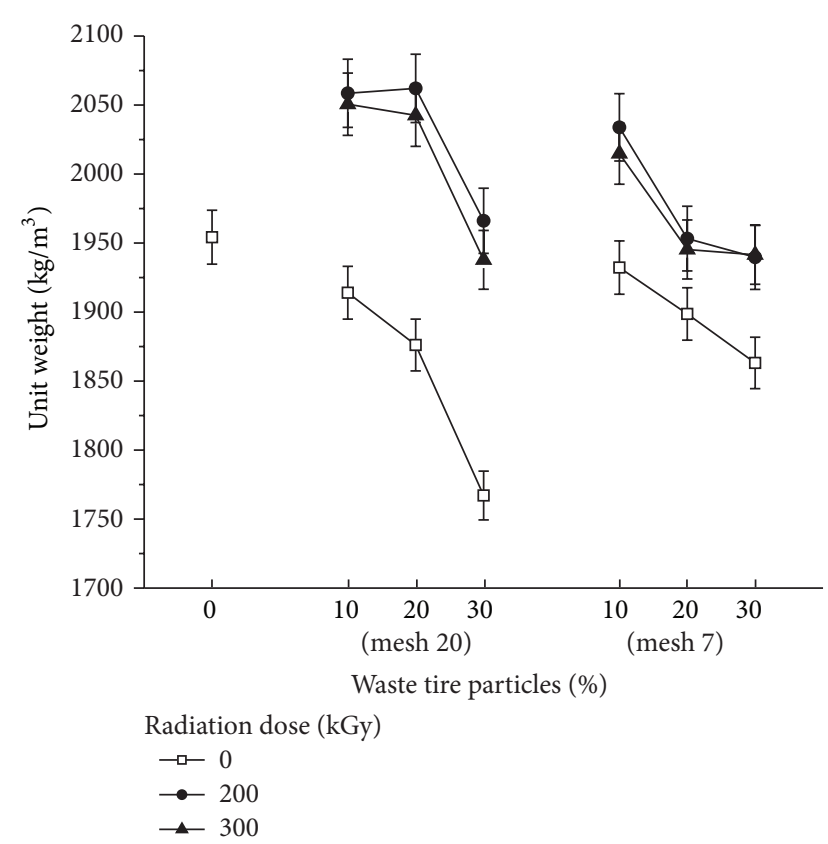

FIGURE 1: Unit weight of concrete with waste tire particles at different irradiated doses.

parameters: concentration and size of the tire particles, as well as irradiation dose. With respect to particle concentration, the unit weight diminishes progressively when it is increasing; reaching the lowest value for concrete with $30 \%$ of particles, the reduction on the values means $10 \%$ lower than those for control concrete $\left(1954 \mathrm{~kg} / \mathrm{cm}^{3}\right)$. Taking into account the particle size, lower values are observed for concrete with small size particles $(0.85 \mathrm{~mm})$. Moreover, all nonirradiated concretes have lower values with respect to the control concrete. Thus, a combination of small particle size and more particle concentration creates lower unit weight of concrete. In fact the values decrease because waste tire particles are porous and then air content is increased in concrete mixtures generating low unit weight. This fact is in accordance with a related research in which the air content in concrete increases when using bigger rubber particles [41].

In the case of concrete with irradiated waste tire particles, highest values are observed for $200 \mathrm{kGy}$, followed by those with irradiated particles at $300 \mathrm{kGy}$. Nevertheless, all irradiated concrete specimens show higher values than nonirradiated ones. The maximum value obtained was $5 \%$ higher than those for control concrete. It is important to mention that during mixing process with irradiated particles some small lumps were formed, different from the control concrete which showed a homogeneous surface. Then modifications on the tire particle surfaces after irradiating cause lumps when mixing to concrete and in consequence higher unit weight is seen.

3.2. Compressive Strength. Compressive strength values of concretes are shown in Figure 2. The compressive strength values vary as a function of size and concentration of waste tire particles. For concrete with nonirradiated waste tire particles, the following behaviors are observed: (a) the

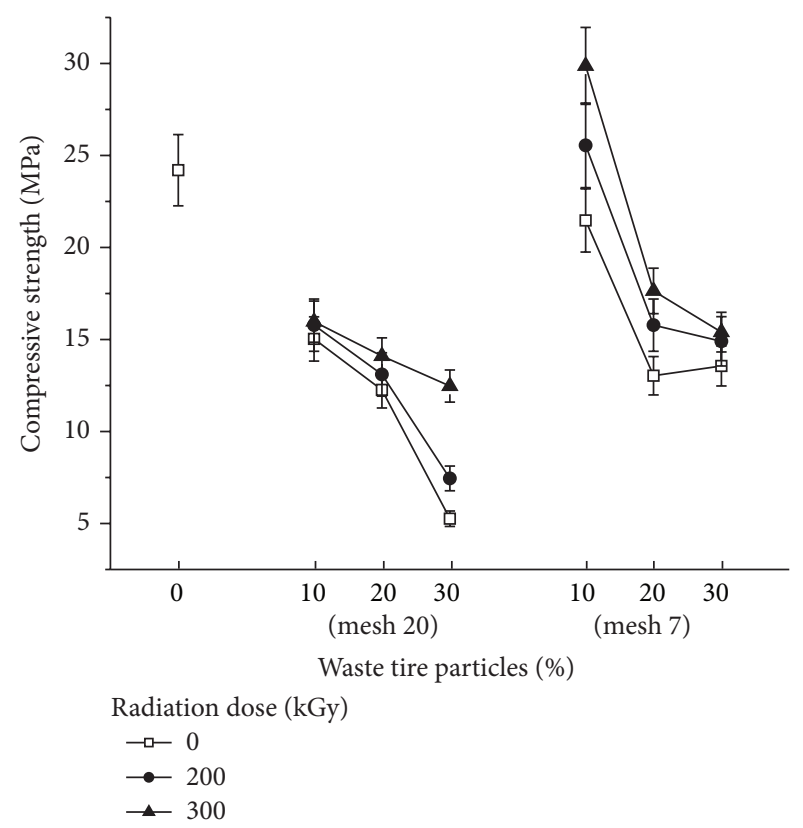

FIGURE 2: Compressive strength of concrete with waste tire particles $0.85 \mathrm{~mm}$ (mesh 20) and $2.8 \mathrm{~mm}$ (mesh 7).

values decrease progressively according to the particle concentrations increase. Moreover, all these kinds of concretes have lower values than those for control concrete, namely, 24.1 MPa; (b) with respect to the particle size, the compressive strength values are higher for concretes with particles of $2.8 \mathrm{~mm}$ than those with $0.85 \mathrm{~mm}$. Thus, when increasing the waste particle concentration and adding large particles more air content is obtained which may cause microcracking and in consequence lower compressive values.

For concrete with irradiated waste tire particles the compressive strength values follow a similar behavior: they increase gradually according to irradiation dose increases. Due to gamma irradiation, the tire particles are progressively harder and no cracks are seen on its surfaces; such behavior generates a composite material with harder particles, which contribute to improving the resistance of the concrete. Additionally, bigger size tire particles create more mechanical resistance compared to smaller ones; such behavior is a consequence of its bigger surface area. It is important to mention that only concretes with $10 \%$ of tire particles of $2.8 \mathrm{~mm}$ and those irradiated at 200 or $300 \mathrm{kGy}$ showed higher values than those for control concrete, up to $23 \%$ of improvement.

3.3. Splitting Tensile Strength. Splitting tensile strength values of concretes are shown in Figure 3. For concrete with nonirradiated waste tire particles, the following behaviors are observed: (a) with respect to particle concentration, the values decrease when increasing the particle concentration; when considering the particle size, higher values are found for concrete with particles of $2.8 \mathrm{~mm}$. However, all values are lower than those for control concrete.

The splitting tensile strength for concrete with irradiated waste tire particles shows a peculiar behavior: at $200 \mathrm{kGy}$ 


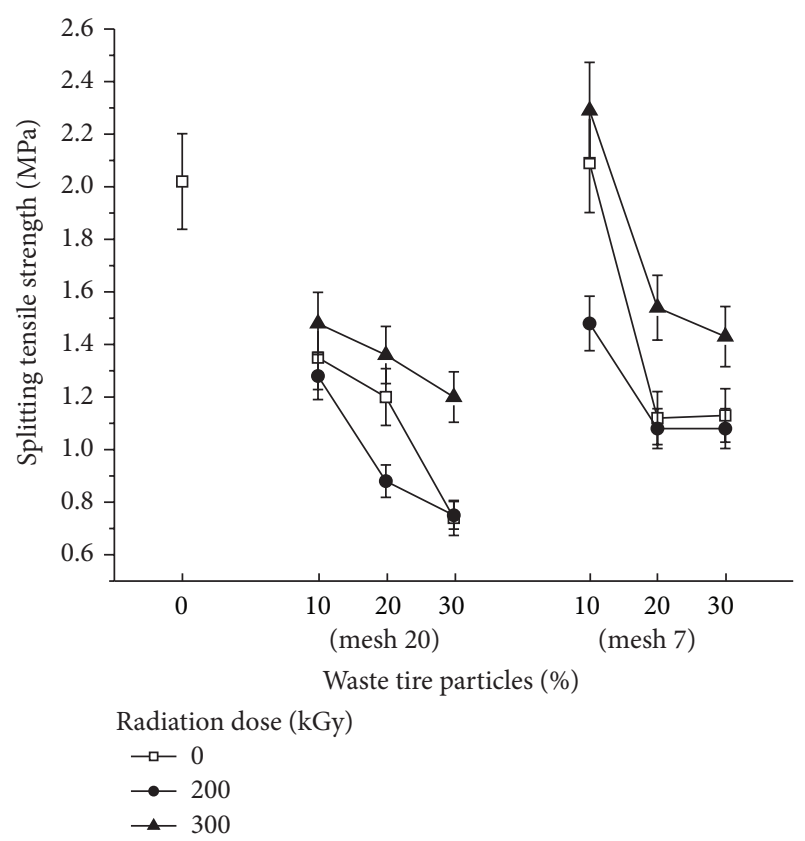

FIGURE 3: Splitting tensile strength of concrete with waste tire particles of $0.85 \mathrm{~mm}$ (mesh 20) and $2.8 \mathrm{~mm}$ (mesh 7).

the values decrease below the control concrete value; nevertheless at $300 \mathrm{kGy}$ the values increase, now above the control concrete value. Such results are dependent on two parameters, the dispersion of particles into the concrete and the morphology changes on the particle surfaces. More structural damage on the particles is caused when applying higher doses. Such behavior of below-above for the values with respect to control concrete depends on the arrangement of the irradiated particles into the concrete; dose of $300 \mathrm{kGy}$ allows a better arrangement and in consequence an increment of the tensile strength up to $13 \%$. Only concretes with $10 \%$ of particles of $2.8 \mathrm{~mm}$ and irradiated at $300 \mathrm{kGy}$ have higher values than those for control concrete.

Figure 4 shows nonirradiated and irradiated particles (at $200 \mathrm{kGy}$ and $300 \mathrm{kGy}$ ). For nonirradiated tire particles a rough surface is observed, containing small particles of different sizes (left image); when irradiating at $200 \mathrm{kGy}$ smooth surfaces are created, with some small and disperse particles. According to the literature, sometimes smooth surfaces are generated after irradiating as consequence of the cross-linking of polymer chains, while for higher dose scissions of the polymer chains are done, which is manifested by appearances of cracks on the surfaces; as it is shown in Figure 4, for $300 \mathrm{kGy}$.

3.4. Flexural Strength. The flexural strength values are shown in Figure 5. The results for concrete without irradiated particles indicate (a) progressive diminution of the values when increasing the concentration of particles; (b) variations in terms of the particle size; higher values are for concretes with particles of $2.8 \mathrm{~mm}$. Inclusively, only concrete with $10 \%$ of waste particles has a higher value than those for control concrete; such improvement is of $10 \%$.
For concrete with irradiated particles the flexural strength values are lower than those for control concrete. Conversely to compressive strength values where the values for concrete with irradiated particles are higher than those for control concrete, in the case of flexural strength, are lower. Thus a combination of particle arrangement (random distribution) and the type of mechanical test may result in higher or lower values. In the case of flexural test the induced stresses generated in the specimens are in the direction of the two load application axes. The diminution on the values is of $46 \%$ with respect to control concrete.

3.5. Modulus of Elasticity. The modulus of elasticity values is shown in Figure 6. As other mechanical features discussed in previous sections, the modulus of elasticity values follows similar behaviors: (a) the values decrease when increasing the concentration of particles; (b) the values are higher for concrete with particles of $2.8 \mathrm{~mm}$. Nevertheless, the values are lower with respect to control concrete. This is due to the fact that the concrete without tire particles is more rigid and does not allow large deformations; nevertheless when adding particles the slope of its stress-strain curve in the elastic deformation region is changing; thus elastic modulus is lower; a stiffer material will have a higher elastic modulus.

For concrete with irradiated particles, modulus of elasticity values has different behaviors: (a) when adding irradiated particles of $0.85 \mathrm{~mm}$, the values increase according to increasing the irradiation dose; (b) when adding large irradiated particles $(2.8 \mathrm{~mm})$, the values for concrete with irradiated particles at $200 \mathrm{kGy}$ are lower with respect to control concrete values but higher for those that are using irradiated particles at $300 \mathrm{kGy}$. Such behaviors can be related to the morphological changes of the irradiated particles as well as their distribution into the concrete. The irradiated particles contribute to incrementing the deformations into the concrete and to diminution of crack formation which results in lower modulus of elasticity. Despite this, improvement of $20 \%$ is obtained for concrete with $10 \%$ of irradiated particles with respect to those for control concrete.

3.6. Pulse Velocity. In Figure 7 the ultrasonic pulse velocities applied to concrete are shown. Results show similar behavior to compressive strength values; as for concrete with nonirradiated particles the values decrease when increasing the concentration of waste tire particles, and they are bigger when using larger particles of $2.8 \mathrm{~mm}$. Nevertheless, the highest value corresponds to control concrete.

In the case of concrete with irradiated waste particles, a similar behavior is observed: the values diminish when increasing the irradiation dose. Detrimental values are 56\% lower with respect to control concrete value. Moreover, the morphological changes on the particles and the increment of their hardness after irradiating contribute to nonpropagation of sound waves.

\section{Conclusions}

The results show that gamma irradiation as well as concentration and size of waste tire particles are adequate tools 


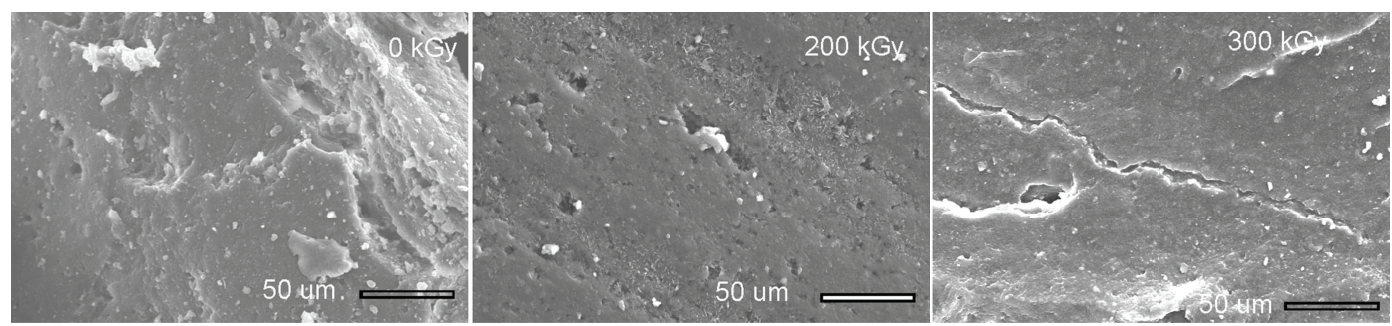

FIGURE 4: SEM image of waste tire particles at different irradiation dose.

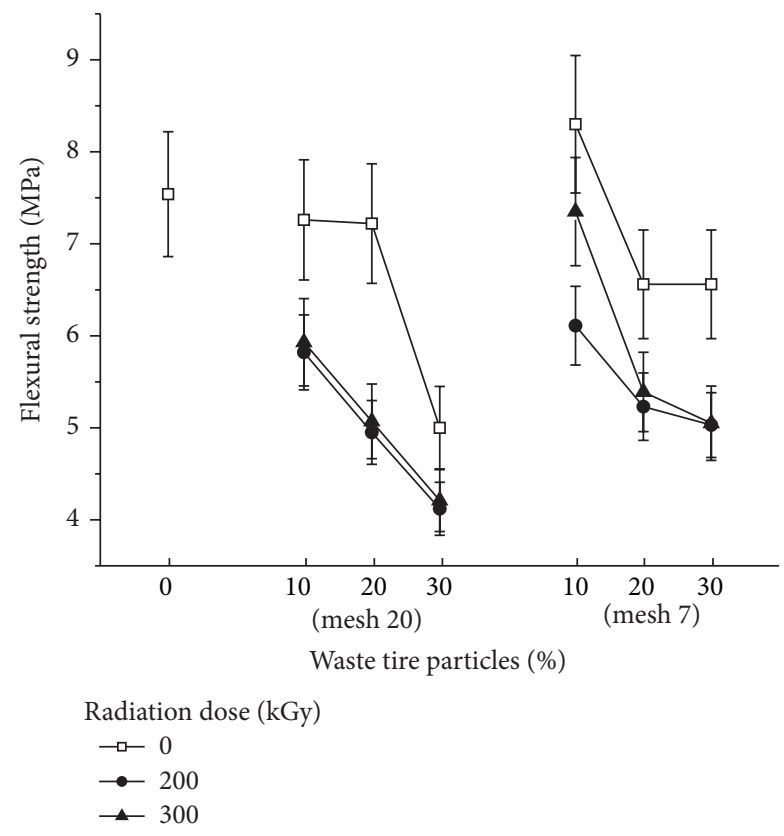

FIGURE 5: Flexural strength of concrete with waste tire particles of $0.85 \mathrm{~mm}$ and $2.8 \mathrm{~mm}$.

for improvement of the mechanical properties of cement concrete. It can be seen that concrete with concentrations no greater than $10 \%$ of particles of $2.8 \mathrm{~mm}$ and irradiated at $300 \mathrm{kGy}$ show the highest values compared to those for the control concrete for compressive strength, tensile strength, and elastic modulus. Different behaviors were observed in terms of the particle sizes and the irradiation doses. In general terms, higher values are obtained with addition of large particles and high irradiation dose. The gamma irradiation generates more homogeneous and smooth surfaces as well as some cracks on the tire particles. Smooth surfaces are related to a hard particle, and the cracks to a better bond between cement matrix and the tire particles; both characteristics can prevent earliest cracks and in consequence soon failures. The morphological characteristics along with the geometrical arrangement of the tire particles into the concrete allow improvements on the mechanical properties.

\section{Conflict of Interests}

The authors do not have a direct financial relation or conflict of interests with the commercial identities mentioned in this

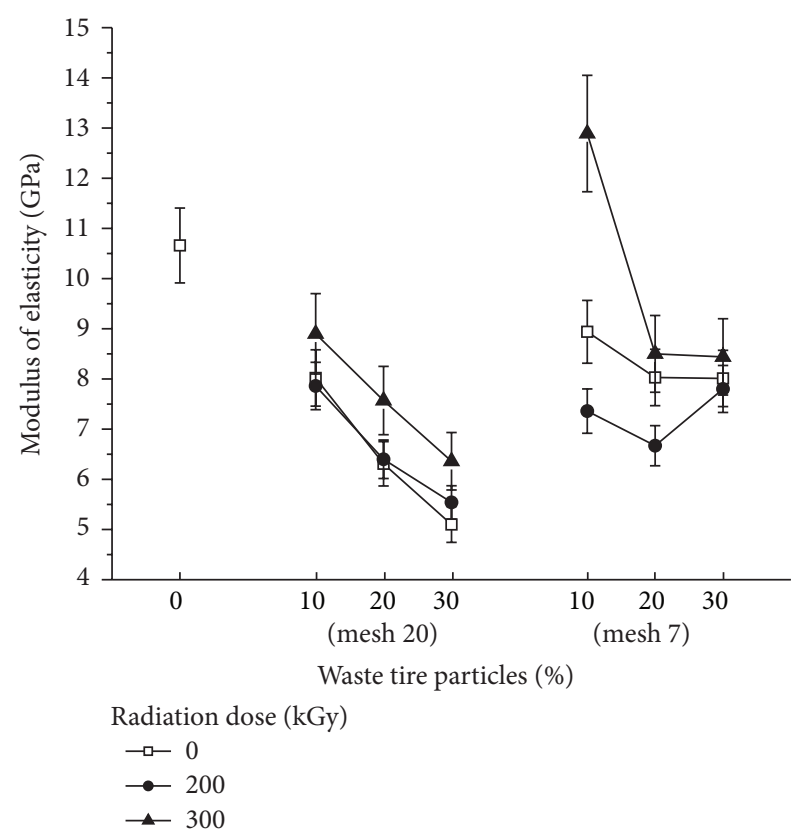

FIgURE 6: Modulus of elasticity of concrete with waste tire particles of $0.85 \mathrm{~mm}$ and $2.8 \mathrm{~mm}$.

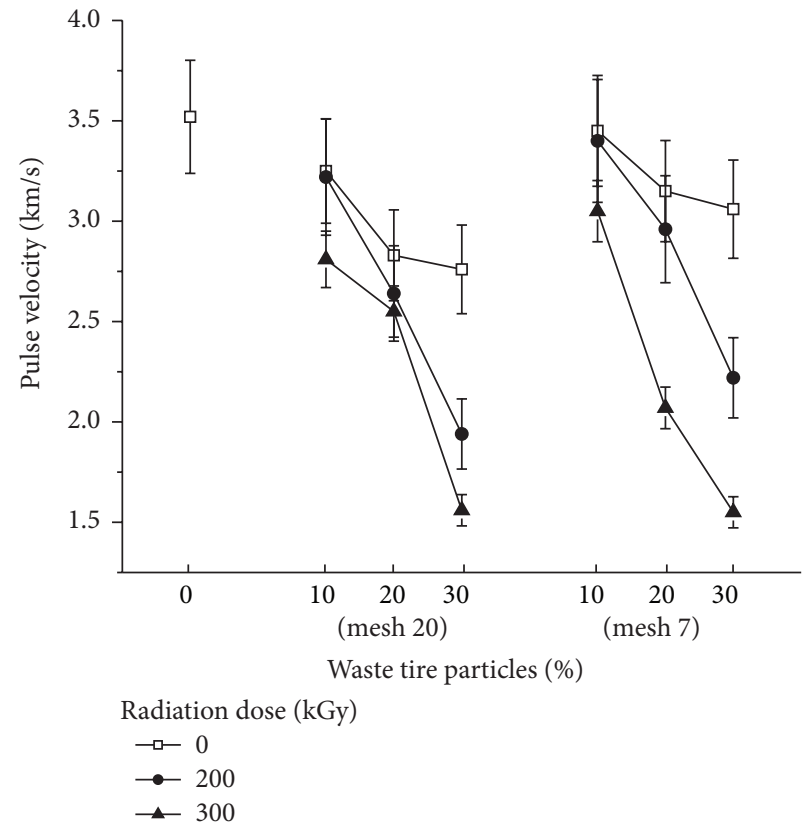

FIGURE 7: Pulse velocity of concrete with waste tire particles of $0.85 \mathrm{~mm}$ and $2.8 \mathrm{~mm}$. 
paper, and the commercial trademarks, such as Controls and Elvec, only were reported to guarantee the reproducibility, in the same conditions, of the different tests.

\section{Acknowledgments}

Thanks are due to the National Council for Science and Technology of México (CONACYT), for both the scholarship support of one of the authors (Eduardo Sadot Herrera-Sosa) and the achievement of this research and to the Environmental Sciences Graduate Program of the Universidad Autónoma del Estado de México (UAEM).

\section{References}

[1] Á. Uruburu, E. Ponce-Cueto, J. R. Cobo-Benita, and J. OrdieresMeré, "The new challenges of end-of-life tyres management systems: a Spanish case study," Waste Management, vol. 33, no. 3, pp. 679-688, 2013.

[2] R. Siddique and T. R. Naik, "Properties of concrete containing scrap-tire rubber-an overview," Waste Management, vol. 24, no. 6, pp. 563-569, 2004.

[3] J. Karger-Kocsis, "Editorial corner-a personal view: waste tyre rubber-what to do next?" Express Polymer Letters, vol. 7, no. 5, article 406, 2013.

[4] R. Mis-Fernandez, J. A. Azamar-Barrios, and C. R. RiosSoberanis, "Characterization of the powder obtained from wasted tires reduced by pyrolysis and thermal shock process," Journal of Applied Research and Technology, vol. 6, no. 2, pp. 95105, 2008.

[5] Ch.-T. Chiu, "Use of ground tire rubber in asphalt pavements: field trial and evaluation in Taiwan," Resources, Conservation and Recycling, vol. 52, no. 3, pp. 522-532, 2008.

[6] K. Neocleous, H. Tlemat, and K. Pilakoutas, "Design issues for concrete reinforced with steel fibers, including fibers recovered from used tires," Journal of Materials in Civil Engineering, vol. 18, no. 5, pp. 677-685, 2006.

[7] M. A. Aiello, F. Leuzzi, G. Centonze, and A. Maffezzoli, "Use of steel fibres recovered from waste tyres as reinforcement in concrete: pull-out behaviour, compressive and flexural strength," Waste Management, vol. 29, no. 6, pp. 1960-1970, 2009.

[8] H. Tlemat, K. Pilakoutas, and K. Neocleous, "Demonstrating steel fibres from waste tyres as reinforcement in concrete: material characterisation," in Proceedings of the 1st International Conference on Innovative Materials and Technologies for Construction and Restoration, Liguori, Ed., vol. 1, pp. 172-185, Varenna, Italy, June 2004.

[9] K. Neocleous, K. Pilakoutas, and P. Waldron, "From used tyres to concrete fibre reinforcement," in Proceedings of the 2nd FIB Congress, Naples, Italy, June 2006.

[10] I. B. Topçu, "The properties of rubberized concretes," Cement and Concrete Research, vol. 25, no. 2, pp. 304-310, 1995.

[11] I. B. Topçu and N. Avcular, "Collision behaviours of rubberized concrete," Cement and Concrete Research, vol. 27, no. 12, pp. 1893-1898, 1997.

[12] B. S. Mohammed, K. M. Anwar Hossain, J. T. Eng Swee, G. Wong, and M. Abdullahi, "Properties of crumb rubber hollow concrete block," Journal of Cleaner Production, vol. 23, no. 1, pp. 57-67, 2012.

[13] F. Pelisser, N. Zavarise, T. A. Longo, and A. M. Bernardin, “Concrete made with recycled tire rubber: effect of alkaline activation and silica fume addition," Journal of Cleaner Production, vol. 19, no. 6-7, pp. 757-763, 2011.

[14] M. Bravo and J. de Brito, "Concrete made with used tyre aggregate: durability-related performance," Journal of Cleaner Production, vol. 25, pp. 42-50, 2012.

[15] A. Benazzouk, O. Douzane, T. Langlet, K. Mezreb, J. M. Roucoult, and M. Quéneudec, "Physico-mechanical properties and water absorption of cement composite containing shredded rubber wastes," Cement and Concrete Composites, vol. 29, no. 10, pp. 732-740, 2007.

[16] M. M. Al-Tayeb, B. H. Abu Bakar, H. M. Akil, and H. Ismail, "Effect of partial replacements of sand and cement by waste rubber on the fracture characteristics of concrete," PolymerPlastics Technology and Engineering, vol. 51, no. 6, pp. 583-589, 2012.

[17] A. R. Khaloo, M. Dehestani, and P. Rahmatabadi, "Mechanical properties of concrete containing a high volume of tire-rubber particles,' Waste Management, vol. 28, no. 12, pp. 2472-2482, 2008.

[18] N. I. Fattuhi and L. A. Clark, "Cement-based materials containing shredded scrap truck tyre rubber," Construction and Building Materials, vol. 10, no. 4, pp. 229-236, 1996.

[19] J. N. Eiras, F. Segovia, M. V. Borrachero, J. Monzó, M. Bonilla, and J. Payá, "Physical and mechanical properties of foamed Portland cement composite containing crumb rubber from worn tires," Materials \& Design, vol. 59, pp. 550-557, 2014.

[20] G. Martínez-Barrera and O. Gencel, "Structural modification of waste materials and its use in building materials," in Photo Cured Materials, A. Tiwari and A. Polykarpov, Eds., pp. 347-359, Royal Society of Chemistry, Cambridge, UK, 2015.

[21] E. Cruz-Zaragoza and G. Martínez-Barrera, "Ionizing radiation effects on the matter and its applications in research and industry," in Gamma Radiation Effects on Polymeric Materials and Its Applications, C. Barrera-Díaz and G. Martínez-Barrera, Eds., pp. 1-14, Research Signpost, Kerala, India, 2009.

[22] S. R. Scagliusi, E. L. C. Cardoso, and A. B. Lugao, "Effect of gamma radiation on chlorobutyl rubber vulcanized by three different crosslinking systems," Radiation Physics and Chemistry, vol. 81, no. 9, pp. 1370-1373, 2012.

[23] H. L. Sui, X. Y. Liu, F. C. Zhong, X. Y. Li, L. Wang, and X. $\mathrm{Ju}$, "Gamma radiation effects on polydimethylsiloxane rubber foams under different radiation conditions," Nuclear Instruments and Methods in Physics Research, Section B: Beam Interactions with Materials and Atoms, vol. 307, pp. 570-574, 2013.

[24] R. L. Clough, "High-energy radiation and polymers: a review of commercial processes and emerging applications," Nuclear Instruments and Methods in Physics Research Section B: Beam Interactions with Materials and Atoms, vol. 185, no. 1-4, pp. 833, 2001.

[25] M. Barbuta and M. Hrja, "Properties of fiber reinforced polymer concrete," Buletinul Institutului Politehnic din Iaşi, vol. 43, pp. 13-22, 2008.

[26] Y. Le Pape, K. G. Field, and I. Remec, "Radiation effects in concrete for nuclear power plants. Part II. Perspective from micromechanical modeling," Nuclear Engineering and Design, vol. 282, pp. 144-157, 2015.

[27] B. Kelly, J. Brocklehurst, D. Mottershead, and S. McNearney, "The effects of reactor radiation on concrete," in Proceedings of the 2nd Information Meeting on Pre Stress Concrete and Reactor Pressure Vessels and their Thermal Isolation, pp. 237-265, Brussels, Belgium, 1969. 
[28] C. Menchaca-Campos, C. E. Barrera-Díaz, G. MartínezBarrera, and O. Gencel, "Influence of irradiated polymeric fibers on the mechanical properties of concretes: analysis by microscopy," in Current Microscopy Contributions to Advances in Science and Technology, A. Méndez-Vilas, Ed., pp. 1123-1129, Formatex Research Center, Badajoz, Spain, 2012.

[29] M. H. P. Gazineu, V. A. dos Santos, C. A. Hazin, W. E. de Vasconcelos, and C. C. Dantas, "Production of polymer-plaster composite by gamma irradiation," Progress in Nuclear Energy, vol. 53, no. 8, pp. 1140-1144, 2011.

[30] L. I. Avila-Córdoba, G. Martínez-Barrera, F. Ureña-Nuñez, and C. E. Barrera-Díaz, "Electron microscopy for the evaluation of concrete surfaces modified by gamma radiation," in Current Microscopy Contributions to Advances in Science and Technology, A. Méndez-Vilas, Ed., pp. 1115-1122, Formatex Research Center, Badajoz, Spain, 2012.

[31] R. Sonnier, E. Leroy, L. Clerc, A. Bergeret, and J. M. LopezCuesta, "Compatibilisation of polyethylene/ground tyre rubber blends by $\gamma$ irradiation," Polymer Degradation and Stability, vol. 91, no. 10, pp. 2375-2379, 2006.

[32] T. Yasin, S. Khan, M. Shafiq, and R. Gill, "Radiation crosslinking of styrene-butadiene rubber containing waste tire rubber and polyfunctional monomers," Radiation Physics and Chemistry, vol. 106, pp. 343-347, 2015.

[33] American Society for Testing Materials (ASTM), "Standard specification for Portland cement," ASTM C 150-07, 2007.

[34] American Concrete Institute, "Standard practice for selecting proportions for normal, heavyweight, and mass concrete," ACI 211.1-91, 2002.

[35] E. S. Herrera-Sosa, G. Martínez-Barrera, C. Barrera-Díaz, and E. Cruz-Zaragoza, "Waste tire particles and gamma radiation as modifiers of the mechanical properties of concrete," Advances in Materials Science and Engineering, vol. 2014, Article ID 327856, 7 pages, 2014.

[36] American Society for Testing Materials (ASTM), "Standard specification for mixing rooms, moist cabinets, moist rooms, and water storage tanks used in the testing of hydraulic cements and concretes," ASTM C511-09, American Society for Testing Materials (ASTM), Philadelphia, Pa, USA, 2009.

[37] American Society for Testing Materials (ASTM), Standard Practice for Making and Curing Concrete Test Specimens in the Laboratory, ASTM C/192/C 192M-00, American Society for Testing Materials (ASTM), West Conshohocken, Pa, USA, 2000.

[38] American Society for Testing Materials (ASTM), Standard Test Method for Compressive Strength of Cylindrical Concrete Specimens, ASTM C 39/C 39M-01, American Society for Testing Materials (ASTM), West Conshohocken, Pa, USA, 2001.

[39] American Society for Testing Materials (ASTM), "Standard test method for flexural strength of concrete (using simple beam with third point loading)," ASTM C 78-00, American Society for Testing Materials (ASTM), Philadelphia, Pa, USA, 2000.

[40] American Society for Testing Materials (ASTM), Standard Test Method for Pulse Velocity Trough Concrete, ASTM C 59709, American Society for Testing Materials (ASTM), West Conshohocken, Pa, USA, 2009.

[41] G. Skripkiunas, A. Grinys, and M. Dauksys, "Using tires rubber waste for modification of concrete properties," in Sustainable Construction Materials and Technologies, Y.-M. Chun, P. Claisse, T. R. Naik, and E. Ganjian, Eds., pp. 85-90, Taylor \& Francis Group, London, UK, 2007. 

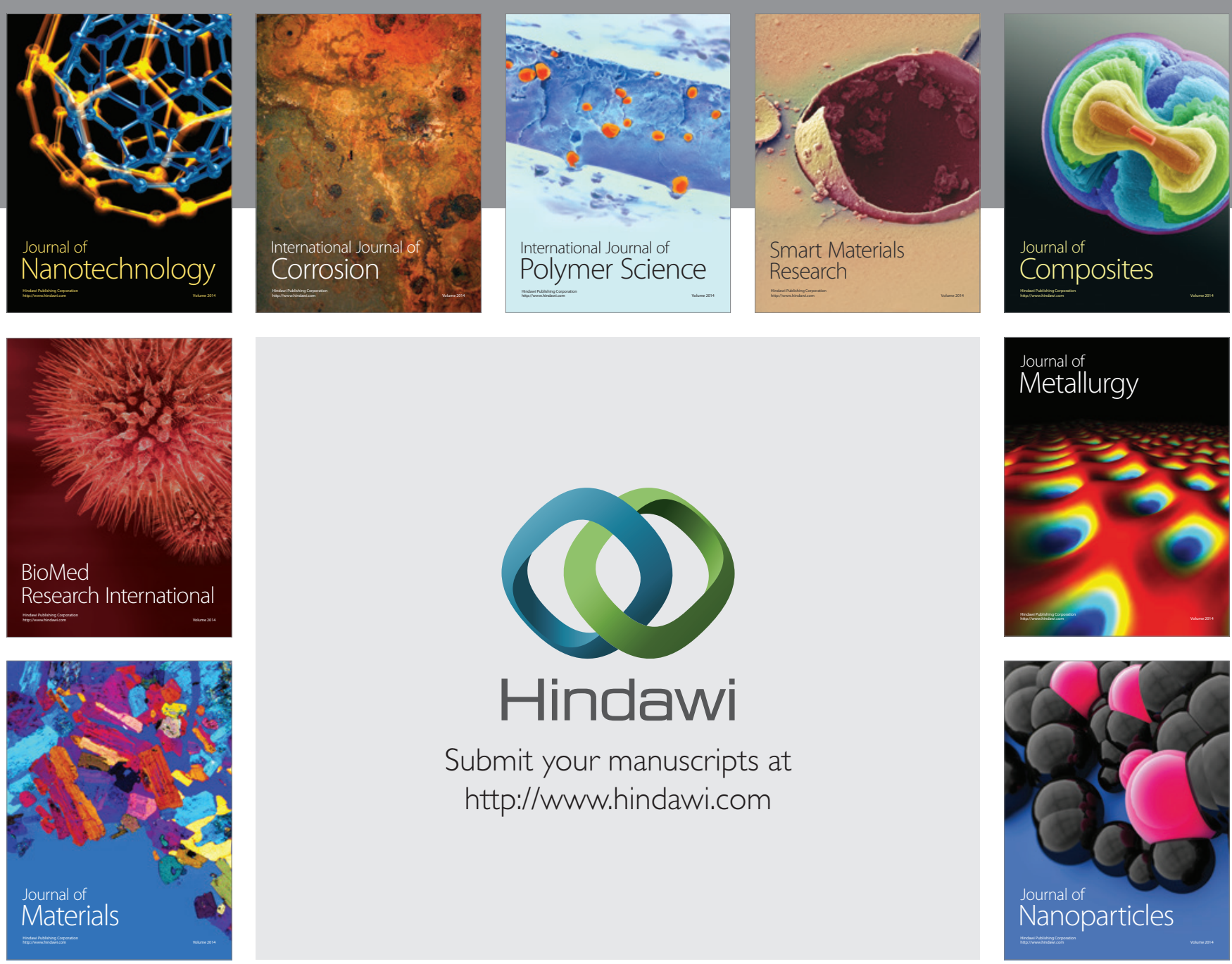

Submit your manuscripts at http://www.hindawi.com
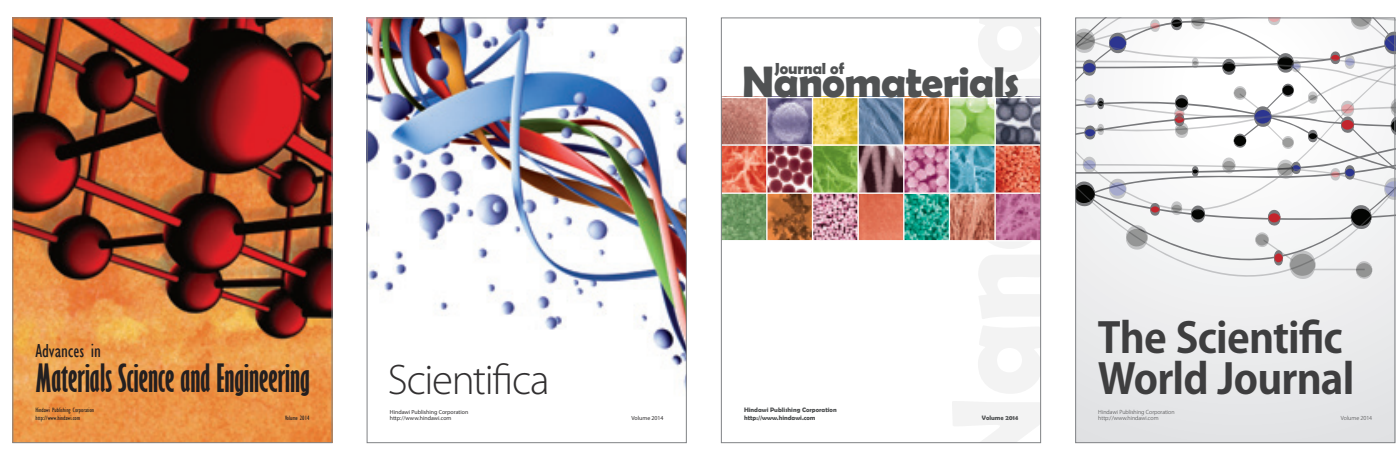

\section{The Scientific World Journal}
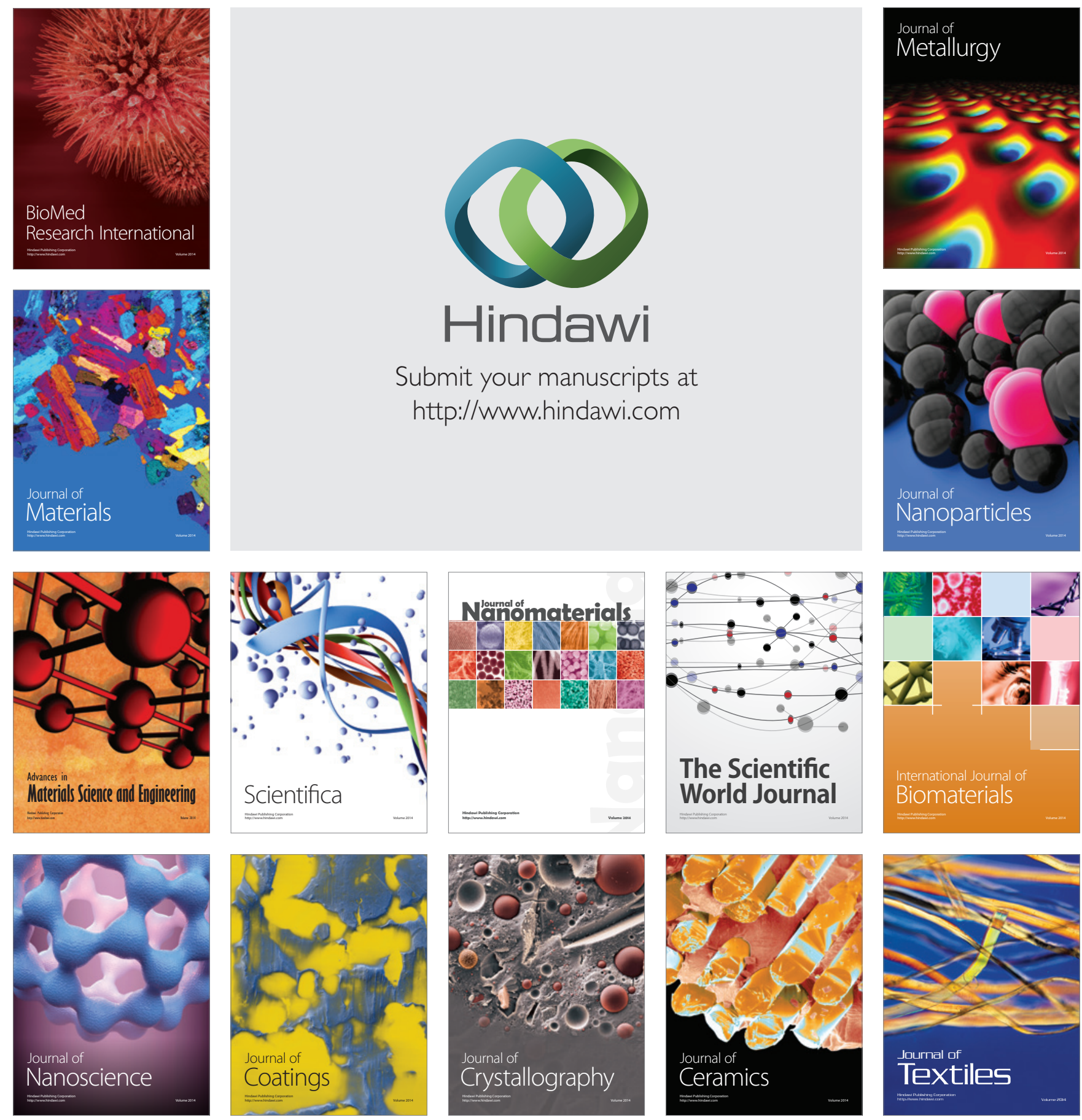